\title{
COVID-19 related fear and mental health in Indian sample: The buffering effect of support system
}

\author{
Alina Suhail ${ }^{1} \cdot$ Kaiser Ahmad $\operatorname{Dar}^{2}$ (iD $\cdot$ Naved Iqbal $^{1}$ (I) \\ Accepted: 29 March 2021 / Published online: 5 April 2021 \\ (C) The Author(s), under exclusive licence to Springer Science+Business Media, LLC, part of Springer Nature 2021
}

\begin{abstract}
The scientific world witnessed a surge of researches, from all corners of the world, regarding the humanitarian crisis precipitated by COVID-19 pandemic, more specifically its impact on people's mental health. However, researchers exploring the association between COVID-19 related fear and mental health are yet to understand the conditions through which potential benefits may occur. Many factors could buffer the effects of COVID-19 related fear on mental health; support system is probably the predominant one. Thus, the present study examined the moderating effects of support system in the association between COVID-19 related fear and mental health outcomes - somatic symptoms, generalized anxiety disorder (GAD), and depression. Using a web-based cross-sectional survey, we collected data from 163 volunteers assessed with demographic information, COVID-19 related fear, support system, and mental health outcomes. Hierarchical multiple regression analysis and simple effect tests revealed that high levels of support from family, friends, and significant others might buffer/lessen the psychological sequelae (e.g., somatic symptoms, anxiety, and depression during public health emergencies, such as COVID-19 pandemic. Given the potential for negative mental health outcomes following pandemics, such as COVID-19, efforts to enhance peoples' support system may be especially important.
\end{abstract}

Keywords Anxiety $\cdot$ Covid-19 related fear $\cdot$ Depression $\cdot$ Somatic symptoms $\cdot$ Support system

\section{Introduction}

The Coronavirus disease, caused by the SARS-CoV-2 (severe acute respiratory syndrome-coronavirus 2 ) has proven to be a 'once-in-a-lifetime pandemic' in the history of humankind (Balkhair, 2020), given the length and breadth of devastation caused thereof. The physical symptoms and the clinical manifestations of COVID-19, which more or less resemble those of SARS and MERS, are almost clear to the medical fraternity (Ashour et al., 2020). Apart from the physical repercussions, the mental illness ramifications of COVID-19 pandemic have garnered the interest of mental health researchers all over the world (Arslan et al., 2020; Tanhan et al., 2020). Pandemics are known to cause mental health problems, irrespective of their

Kaiser Ahmad Dar

kaisjmi@gmail.com

1 Department of Psychology, Jamia Millia Islamia, New Delhi 110025, India

2 Department of Psychology, Government Degree College Baramull, Baramulla, Jammu and Kashmir 193103, India nature and type, and COVID-19 is no exception. As asserted by researchers, outbreak of such pandemics are most often associated with the deterioration of mental health and wellbeing in people (Rajkumar, 2020). The ongoing COVID-19 pandemic has reportedly instigated mental health crisis ' ... at individual, community, national, and international levels' (Salari et al., 2020). Researchers, such as Bao et al. (2020), Huang and Zhao (2020), and Wang et al. (2020) have posited that COVID-19 has, indeed, led to the development of mental illness and extreme psychological distress in the general population. In the present context, distress amongst the general population is primarily an outcome of fear, insecurity, depression, and anxiety (Zhang et al., 2020). In fact, researchers have identified anxiety as the most frequently occurring emotional response to COVID-19 borne psychological distress, which is often accompanied by sleep disturbances (Lima et al., 2020; Xiao et al., 2020). Recent evidence suggests that isolation and quarantine experiences have led to the development of extreme stress, confusion, and anger amongst people (Brooks et al., 2020). Other mental health concerns associated with COVID-19 include irritability, mood fluctuation, post-traumatic stress, and attention-deficit hyperactivity disorder (Brooks et al., 2020; Rubin \& Wessely, 2020). Apart 
from the direct mental health ramifications of the pandemic, research has also identified the role of poorly perceived health, misinformation, unpredictability, and media exposure in determining the development of distress and mental morbidity (Wang et al., 2020; Zandifar \& Badrfam, 2020).

Notably, the pandemic borne situation is a global affair and not restricted to particular countries or regions. If we talk about the Indian subcontinent, mental health crisis triggered by COVID-19 are serious and detrimental. Roy et al. (2020), for instance, suggest the presence of serious mental health issues amongst the general population, in the form of compulsive hoarding, paranoia, sleeping difficulties, anxiety, and constant worrying. Indian researchers have actively focused on at-risk groups, mainly healthcare workers. Such investigations point towards mental health complexities, such as anxiety, sleep disturbances, and depression, along with fear of contracting the virus, physical and mental fatigue, burnout, and frustration (Banerjee, 2020; Sarangi, 2020). Other Indian researchers have raised concerns regarding the onset of illness anxiety disorder in the general population and morbidities in people with substance use disorders (Chatterjee et al., 2020; Kumar \& Nayar, 2020).

It is reasonable to assert that the mental health repercussions of COVID-19 emerge out of the fear triggered by the entire situation. Asmundson and Taylor (2020) talk about 'coronaphobia', which can be understood as '....an emotion construct based on fear and anxiety'. Indeed, fear has consistently acted as an amplifier in the case of mental health crisis that arose due to COVID-19 (Ahorsu et al., 2020). Fear of contracting the virus has led to a multitude of problems, including stigma and discrimination (Lin, 2020). Evidently, COVID-19-related fears multiply as the transmission rate increases, causing the fearful individuals to act irrationally (Ahorsu et al., 2020). It can be asserted that if the situation continues to unfold the way it is presently unfolding, COVID19-related fears will exacerbate and create emotional chaos amongst the general population. Apart from understanding the traditional interplay between COVID-19-related fears and mental health outcomes, it is optimally important to explore the boundary conditions to understand the nature of this relationship.

One possible boundary conditions between COVID-19related fears and mental health appears to be individual support system. Social support is often defined as the amount of support a person perceives and acknowledges receiving it (Harandi et al., 2017). A person's support system has a significant role to play in the way they interact in a social set-up, which in turn plays an important part in determining mental health (Marmot \& Wilkinson, 2005). Brummett et al. (2005) assert that one of the key features of a support system is that it reassures the individual of the availability of physical and psychological buffer. The authors further posit that since support system provides a sense of security to the individuals experiencing psychosocial and physical distress, it directly improves the individual's mental well-being. Although researchers, such as, El-Zoghby et al. (2020) and Xiao et al. (2020) investigated social support in the context of COVID19 , the construct has been treated as either an outcome or a predictor variable. It is, therefore, plausible to investigate the role of support system as a moderating factor, in order to have a better understanding of the interplay between COVID-19related fears and mental health.

\section{The Present Research}

The current study was designed to examine the additive and interactive relations of COVID-19 related fear and support system with Indian populations' mental health outcomes during COVID-19 outbreak. Not only at risk groups/populations but the general population in India were exposed to a significant amount of COVID-19 related fears during the outbreak. In addition, most of the research focus has been on at risk populations in India or other pockets of the globe. Thus, the current study deemed it appropriate to study mental health outcomes in general population during the COVID-19 outbreak.

Based on the literature review, we hypothesized, that (a) COVID-19 related fear would be negatively associated with support system (family support, friends' support, and significant others' support) and positively associated with mental health outcomes, (b) support system would be negatively associated with mental health outcomes, and (c) COVID-19 related fear would interact with support system such that strong support system would buffer the negative effects of COVID-19 related fear on mental health outcomes.

\section{Method}

\section{Participants}

For the purpose of data collection, an online survey was conducted using Google forms. The Google forms link was shared via WhatsApp and Gmail platforms and other social media handles. Participants answered the questionnaires from July 9 to 13, 2020. All subjects reported their demographic data and completed five standardized questionnaires, which assessed their COVID-19 related fear, support system, and mental health. Finally, 163 participants who completed the questionnaires were included in the analysis. Participants' age ranged from 16 years to 45 years $(M=26.64$ years, $S D=6.19$ years). Demographic characteristics of participants are presented in Table 1 . 
Table 1 Baseline characteristics of 163 enrolled participants in the study $(N=163)$

\begin{tabular}{|c|c|c|c|c|c|c|}
\hline \multirow[t]{2}{*}{ Gender } & \multicolumn{4}{|c|}{ Marital status } & \multirow[b]{2}{*}{$\chi^{2}$} & \multirow[b]{2}{*}{$\Phi$} \\
\hline & Married & Single & Divorced/Separated & Dating/Engaged & & \\
\hline \multirow[t]{2}{*}{ Male } & 27 & 42 & 1 & 5 & \multirow[t]{4}{*}{7.78} & \multirow[t]{4}{*}{.22} \\
\hline & (19.3) & $(48.3)$ & (.9) & (6.4) & & \\
\hline \multirow[t]{2}{*}{ Female } & 15 & 63 & 1 & 9 & & \\
\hline & $(22.7)$ & $(56.7)$ & $(1.1)$ & (7.6) & & \\
\hline
\end{tabular}

\section{Power Analysis}

An a priori power analysis using the $G^{*}$ Power computer program (Faul et al., 2007) indicated that a total sample of 118 participants were needed to detect medium effects $\left(\mathrm{f}^{2}=.15\right)$, with $80 \%$ power using a hierarchical multiple regression, fixed model, $R^{2}$ change, and an alpha of .05. Thus, our actual sample size, $N=163$ was more than adequate for the main objectives of this study.

\section{Measures}

\section{COVID-19-Related Fear}

The COVID-19 related fear was measured using Fear of COVID-19 Scale (FCV-19S; Ahorsu et al., 2020). This 7 -item scale is used to measure fears related to the ongoing COVID-19 pandemic. Participants are asked to rate the extent to which they have been bothered by each item during the pandemic on a five-point scale ranging from 1 (strongly disagree) to 5 (strongly agree). Total score ranged from 7 to 35 . Item factor loads of the original scale range from .66 to .74 and item total correlations vary between .47 and .56 . In the present study, the FCV-19S had good internal consistency reliability (Cronbach's alpha $=.87$ ).

\section{Somatic Symptoms}

The Somatic Symptom Scale-8?> (SSS-8; Gierk et al., 2014) was used to assess the participants for stomach problems, fatigue, back pain, headache, sleeping troubles, dizziness, shortness of breath, and pain in arms, legs, and joints. The SSS-8 is an 8-item self-report questionnaire, rated on a fivepoint Likert scale, ranging from 0 (not at all) to 4 (very much). The SSS- 8 is derived from the frequently used Patient Health Questionnaire-15 (PHQ-15), developed by Spitzer and colleagues under Pfizer, INC (Kroenke et al., 2010). In the present study, the SSS-8 had good internal consistency reliability (Cronbach's alpha $=.81$ ).

\section{Anxiety}

The Generalized Anxiety Disorder-7 (GAD-7; Spitzer et al., 2006) was used to measure generalized anxiety. GAD-7 is a $7-$ item measure, rated on a four-point Likert scale, ranging from 0 (not at all) to 3 (nearly every day). Initially, Spitzer et al. (2006) had constructed a 13-item scale, before they compressed it to a total of 7 items. The authors found both the versions highly correlated to each other ( $r=.75$ to .85$)$. For GAD-7, the authors reported a good test-retest reliability, with the interclass correlation $=.83$. In the present study, the SSS-8 had good internal consistency reliability (Cronbach's alpha $=.90)$.

\section{Depression}

The Centre for Epidemiologic Studies Depression Scale (CESD; Radloff, 1977) was used to measure depressive symptomatology. The CES-D has a significant construct validity and high internal consistency with Cronbach's alpha ranging between .85 and .90 . The CES-D is a 20-item measure, rated on a four-point Likert scale, with responses ranging from 0 (rarely or none of the time) to 3 (most or all of the time). The scale measures six facets of depression: depressed mood, feelings of guilt and worthlessness, feelings of helplessness and hopelessness, psychomotor retardation, loss of appetite, and sleep disturbance. In the present study, the SSS- 8 had good internal consistency reliability (Cronbach's alpha $=.91$ ).

\section{Support System}

The Multidimensional Scale of Perceived Social Support (MSPSS; Zimet et al., 1988) was used to measure the support system from three sources: family, friends, and significant others. This is a 12-items measure, rated on a seven-point Likert scale from 1 (very strongly disagree) to 7 (very strongly agree). Wang et al. (2017) validated the scale, where the Cronbach alpha coefficients of all the three subscales were found to be $.88, .89$, and .87 , respectively. In the present study, the Cronbach alphas were $.88, .92$, and .93 for family, friends, and significant others subscales, respectively. 


\section{Ethical Considerations}

We declare that the university's institutional review board governing research on living matter has determined that the study protocol adheres to ethical principles. Moreover, the procedures followed were also in accordance with the ethical standards of the Helsinki Declaration of 1975, as revised in 2013.

\section{Procedure}

The study was conducted online because of the restrictions posed by the strict observation of lockdown in India. The data was collected using questionnaires that were converted into Google forms. The demographic information was collected with the help of a data sheet, prepared by the researchers. The very first section of the online form was dedicated to describing the aims of the research and seeking consent from the potential participants. Certain categories of participants were not considered or excluded from participation in the current study. These include nonconsenting individuals, nonIndians, and Indians not residing in India at the time of data collection. Moreover, individuals with pre-existing physical and mental illnesses that required medication were also excluded from participation. Individuals who consented for the present study filled up the survey questions sent through Google forms.

\section{Data Analytic Strategy}

We used moderated regression analysis, the recommended method for testing interaction/moderation effects (Cohen et al., 2013). Three hierarchical regression analyses (Baron \& Kenny, 1986; Cohen et al., 2013) were performed to detect main and moderation/interaction effects of FCV-19S and support system, such as family support $\left(\mathrm{FS}^{1}\right)$, friends' support $\left(\mathrm{FS}^{2}\right)$ and significant others' support (SOS) on mental health such as, somatic symptoms, generalized anxiety disorder (GAD), and depression. If a moderation effect existed, simple effect tests were conducted to test the significant levels of simple slopes. We used SPSS-20 and Hayes's (2018) Process Procedure for SPSS Release 3.5 for data analyses.

\section{Results}

\section{Data Screening}

Before any statistical enterprise, we assessed the data for normality by examining the skewness and kurtosis of the distribution for each measure. All study measures were deemed approximately normally distributed. The assumptions of linearity and homoscedasticity were verified through the examination of bivariate scatterplots between the study measures. These assumptions were met for all measures. All variance-inflation factors in our regressions were below 3 ; this suggests that multicollinearity was not an issue in our analyses.

\section{Preliminary Analyses}

Means, standard deviations, and bivariate correlations for the study's variables are shown in Table 2. Correlation analyses were used to examine the differential relationships between study measures. All the alpha coefficients show reasonable internal consistency, with all of them above the .70 recommended (Nunnaly, 1994). Roughly, half of the correlations turned significant and the direction of these correlations was mixed, and therefore, partly coincided with that expected from the literature reviewed. Cross-tabulation with Chi-squared test was used for categorized variables (gender and marital status; see Table 1). Gender and marital status as demographic variables were included in correlation analysis to determine whether to include them in subsequent analyses. Gender was significantly related to somatic symptoms, anxiety (GAD), and depression. Marital status had more than two categories and was dummy coded before running a correlation analysis such that three dummy variables were created, that is, Marital Status $^{\mathrm{a}}$ (Single versus Married), Marital Status ${ }^{\mathrm{b}}$ (Divorced/ Separated versus Married), and Marital Status ${ }^{\mathrm{c}}$ (Dating/ Engaged versus Married). Marital Status ${ }^{\mathrm{a}}$ and Marital Status ${ }^{\mathrm{c}}$ showed significant association with a reasonable number of study variables. Because of the significant relationship of gender, Marital Status ${ }^{\mathrm{a}}$, and Marital Status ${ }^{\mathrm{c}}$ with predictor/ outcome variables, these demographic variables were controlled for in subsequent analysis. However, Marital Status ${ }^{\mathrm{b}}$ was dropped for subsequent analysis as it failed to show any association with study's variables.

\section{Test for Moderation}

We constructed three separate hierarchical regression models to examine whether $\mathrm{FS}^{1}, \mathrm{FS}^{2}$, and SOS moderated the effects of FCV-19S on somatic symptoms, GAD, and depression. Following Aiken et al., 1991, we centered the predictor FCV-19S including moderators before analysis to control for possible multicollinearity among predictors and moderators. Following this, three interaction terms were created. These include FCV-19S $\times \mathrm{FS}^{1}, \mathrm{FCV}-19 \mathrm{~S} \times \mathrm{FS}^{2}$, and FCV-19S $\times$ SOS by multiplying the predictor with each moderator.

Furthermore, when either somatic symptoms, anxiety (GAD), or depression was the criterion, at Step 1, the demographics - gender, Marital Status ${ }^{\mathrm{a}}$ and Marital Status ${ }^{\mathrm{c}}$ were entered. At Step 2, FCV-19S was entered. At Step 3, FS ${ }^{1}, \mathrm{FS}^{2}$, and SOS were entered. Finally, at Step 4, FCV-19S $\times$ FS $^{1}$, FCV-19S $\times$ FS $^{2}$, and FCV-19S $\times$ SOS were entered. 
Table 2 Descriptive statistics and correlations for study variables $(N=163)$

\begin{tabular}{|c|c|c|c|c|c|c|c|c|c|c|c|c|c|}
\hline Variable & Mean & $S D$ & 1 & 2 & 3 & 4 & 5 & 6 & 7 & 8 & 9 & 10 & 11 \\
\hline 1. FCV-19S & 14.53 & 5.62 & .87 & $.16^{*}$ & $.33^{* *}$ & $.18^{*}$ & -.06 & -.04 & -.05 & -.15 & -.01 & .06 & .05 \\
\hline 2. SSS-8 & 7.88 & 5.48 & & .81 & $.44^{* *}$ & $.38 * *$ & $-.21 * *$ & $-.20 *$ & -.01 & $-.32 * *$ & -.03 & .01 & $.28^{* *}$ \\
\hline 3. GAD-7 & 6.67 & 5.58 & & & .90 & $.65 * *$ & $-.36^{* *}$ & $-.18^{*}$ & $-.16^{*}$ & $-.17^{*}$ & .08 & -.12 & $.23 * *$ \\
\hline 4. CES-D & 19.41 & 10.15 & & & & .91 & $-.30 * *$ & -.12 & $-.18^{*}$ & -.09 & $.18^{*}$ & -.04 & $.23 * *$ \\
\hline 5. $\mathrm{FS}^{1}$ & 21.70 & 5.66 & & & & & .88 & $.43 * *$ & $.41 * *$ & .15 & $-.25^{* *}$ & .01 & .03 \\
\hline 6. $\mathrm{FS}^{2}$ & 21.88 & 5.33 & & & & & & .92 & $.57 * *$ & .08 & -.15 & -.02 & .13 \\
\hline 7. SOS & 21.57 & 6.20 & & & & & & & .93 & -.08 & $-.34 * *$ & -.01 & $.16^{*}$ \\
\hline 8. Gender & na & na & & & & & & & & na & $-.16^{*}$ & .01 & -.06 \\
\hline 9. Marital Status ${ }^{\mathrm{a}}$ & na & na & & & & & & & & & na & -.15 & $-.41 * *$ \\
\hline 10. Marital Status ${ }^{\mathrm{b}}$ & na & na & & & & & & & & & & na & -.03 \\
\hline 11. Marital Status ${ }^{\mathrm{c}}$ & na & na & & & & & & & & & & & na \\
\hline
\end{tabular}

FCV-19S: Fear of COVID-19 Scale; SSS-8: Somatic Symptoms Scale-8 GAD-7: Generalized Anxiety Disorder-7; FS ${ }^{1}$ : Family Subscale: FS ${ }^{2}$ : Friends Subscale; SOS: Significant Other Subscale. Numbers along the diagonal are internal consistencies of the scales

Gender was coded as $1=$ Women, $2=$ Men. Marital status was dummy coded, such that Marital Status ${ }^{\mathrm{a}}=$ Single (coded 1$)$ versus Married (coded 0); Marital Status $\mathrm{s}^{\mathrm{b}}=$ Divorced/Separated $(\operatorname{coded} 1)$ versus Married $(\operatorname{coded} 0)$; Marital Status ${ }^{\mathrm{c}}=$ Dating/Engaged $($ coded 1$)$ versus Married (coded 0).

$* p<.05 . * * p<.001$

Nevertheless, only statistically significant interaction effects are reported and summarized.

\section{Somatic Symptoms as a Dependent Variable}

The results indicated that the entered variables together could explain $27 \%$ of the variance in somatic symptoms (see Table 3). The main effects of gender, Marital Status ${ }^{c}$, and $\mathrm{FS}^{2}$ were significant and maintained this pattern even when interaction terms were introduced in the model. The relationship between gender and somatic symptoms was stronger for females and those engaged or dating compared to males and married, respectively. The association between $\mathrm{FS}^{2}$ and somatic symptoms was significant, such that low $\mathrm{FS}^{2}$ inflated the somatic symptoms.

As regards moderation effects, the $\Delta R^{2}$ could not reach the conventional level of significance; however, the regression coefficient for the interaction of $\mathrm{FCV}-19 \mathrm{~S} \times \mathrm{FS}^{1}$ was significant in predicting somatic symptoms $(p=.035)$. Based on Hayes (2018) recommendations, we used one standard deviation below and above the mean for the variables to plot the nature of the interaction. We also tested the statistical significance of the simple slopes (Aiken et al., 1991; Cohen et al., 2013; Frazier et al., 2004). As seen in Fig. 1, the results from a simple effect analysis supported the moderation hypotheses for somatic symptoms, showing that the association between FCV-19S and somatic symptoms was significant at low $(b=.29, p=.005)$ and non-significant at high $(b=-.10, p=.305)$ levels of $\mathrm{FS}^{1}$.

\section{Anxiety (GAD) as a Dependent Variable}

The pattern of results for GAD was relatively different from those obtained in case of somatic symptoms (see Table 4). Results showed that the entered variables together, accounted for $35 \%$ of the variance in GAD. The main effects of Marital Status $^{\mathrm{a}}$, Marital Status ${ }^{\mathrm{c}}, \mathrm{FCV}-19 \mathrm{~S}$, and $\mathrm{FS}^{1}$ were significant, however, Marital Status ${ }^{a}$ turned non-significant when moderators were included in the model. Results showed that the relationship between Marital Status ${ }^{c}$ and GAD was more robust for engaged/dating participants against their married counterparts. The results revealed that increment in FCV$19 \mathrm{~S}$ and decrement in $\mathrm{FS}^{1}$ inflated the GAD features.

We also found support for moderation effect because the regression coefficient for the interaction of FCV-19S and SOS was significant in predicting GAD $(p=.043)$. Because of the presence of a moderation effect, a simple effect analysis was conducted. The results are illustrated in Fig. 2. When the SOS was low, the association between FCV-19S and GAD was significant $(b=.43, p<.001)$, however, as the SOS increased, this association turned non-significant $(b=.08, p=.461)$.

\section{Depression as a Dependent Variable}

The results relating to depression show a pattern of results very similar to that obtained in case of anxiety (see Table 5). The results revealed that the entered variables together, accounted for $28 \%$ of the variance in depression. The main effects of Marital Status ${ }^{\mathrm{a}}$, Marital Status ${ }^{\mathrm{c}}, \mathrm{FCV}_{-19 S}$, and FS ${ }^{1}$ were significant. Results showed that single and dating/ engaged reported more depression than those who were 
Table 3 Hierarchical regression results for somatic symptoms. $(N=163)$

\begin{tabular}{|c|c|c|c|c|c|c|c|c|}
\hline \multirow[t]{2}{*}{ Variable } & \multirow[t]{2}{*}{$B$} & \multicolumn{2}{|c|}{$95 \%$ CI for $B$} & \multirow[t]{2}{*}{$S E B$} & \multirow[t]{2}{*}{$\beta$} & \multirow[t]{2}{*}{$s r^{2}$} & \multirow[t]{2}{*}{$R^{2}$} & \multirow[t]{2}{*}{$\Delta R^{2}$} \\
\hline & & Lower & Upper & & & & & \\
\hline Step 1 & & & & & & & .17 & $.17 * * *$ \\
\hline Gender & $-3.30 * * *$ & -4.90 & -1.70 & .81 & -.30 & .09 & & \\
\hline Marital Status $^{\mathrm{a}}$ & .38 & -1.44 & 2.20 & .92 & .03 & .00 & & \\
\hline Marital Status ${ }^{\mathrm{c}}$ & $5.34 * *$ & 2.67 & 8.42 & 1.56 & .27 & .06 & & \\
\hline Step 2 & & & & & & & .18 & .01 \\
\hline Gender & $-3.14 * * *$ & -4.75 & -1.52 & .82 & -.29 & .08 & & \\
\hline Marital Status ${ }^{\mathrm{a}}$ & .40 & -1.42 & 2.22 & .92 & .04 & .00 & & \\
\hline Marital Status ${ }^{\mathrm{c}}$ & $5.29 * *$ & 2.22 & 8.36 & 1.56 & .27 & .06 & & \\
\hline FCV-19S & .10 & -.04 & .24 & .07 & .10 & .01 & & \\
\hline Step 3 & & & & & & & .24 & $.06^{*}$ \\
\hline Gender & $-2.65 * *$ & -4.28 & -1.03 & .82 & -.24 & .05 & & \\
\hline Marital Status ${ }^{\mathrm{a}}$ & .28 & -1.63 & 2.19 & .97 & .03 & .00 & & \\
\hline Marital Status ${ }^{\mathrm{c}}$ & $5.54 * * *$ & 2.52 & 8.57 & 1.53 & .29 & .06 & & \\
\hline FCV-19S & .09 & -.04 & .23 & .07 & .10 & .01 & & \\
\hline $\mathrm{FS}^{1}$ & -.12 & -.28 & .04 & .08 & -.12 & .01 & & \\
\hline $\mathrm{FS}^{2}$ & $-.23^{*}$ & -.41 & -.05 & .09 & -.22 & .03 & & \\
\hline SOS & .11 & -.06 & .27 & .08 & .12 & .01 & & \\
\hline Step 4 & & & & & & & .27 & .03 \\
\hline Gender & $-2.69 * *$ & -4.31 & -1.07 & .82 & -.25 & .05 & & \\
\hline Marital Status ${ }^{\mathrm{a}}$ & .43 & -1.48 & 2.33 & .96 & .04 & .00 & & \\
\hline Marital Status ${ }^{\mathrm{c}}$ & $5.84 * * *$ & 2.84 & 8.84 & 1.52 & .30 & .07 & & \\
\hline FCV-19S & .09 & -.05 & .23 & .07 & .10 & .01 & & \\
\hline $\mathrm{FS}^{1}$ & -.12 & -.28 & .04 & .08 & -.13 & .01 & & \\
\hline $\mathrm{FS}^{2}$ & $-.22 *$ & -.40 & -.03 & .09 & -.21 & .03 & & \\
\hline SOS & .10 & -.06 & .27 & .08 & .12 & .01 & & \\
\hline $\mathrm{FCV}-19 \mathrm{~S} \times \mathrm{FS}^{1}$ & $-1.02 *$ & -1.97 & -.07 & .48 & -.18 & .02 & & \\
\hline$F C V-19 S \times F^{2}$ & .04 & -.94 & 1.02 & .50 & .01 & .00 & & \\
\hline FCV $-19 S \times$ SOS & -.09 & -1.04 & .86 & .48 & -.02 & .00 & & \\
\hline
\end{tabular}

married. In addition, FCV-19S was positively and $\mathrm{FS}^{1}$ negatively associated with depression.

The regression coefficient for the interaction of FCV-19S and $\mathrm{FS}^{2}$ was significant in predicting depression $(p=.035)$, thus, supporting the moderation effect. A simple effect

analysis was conducted and the results are illustrated in Fig. 3. At low levels of $\mathrm{FS}^{2}$, the relationship between FCV-19S and depression was significant $(b=.71$, $p<.001)$, and this association turned non-significant $(b=-.16, p=.391)$ at high levels of $\mathrm{FS}^{2}$.

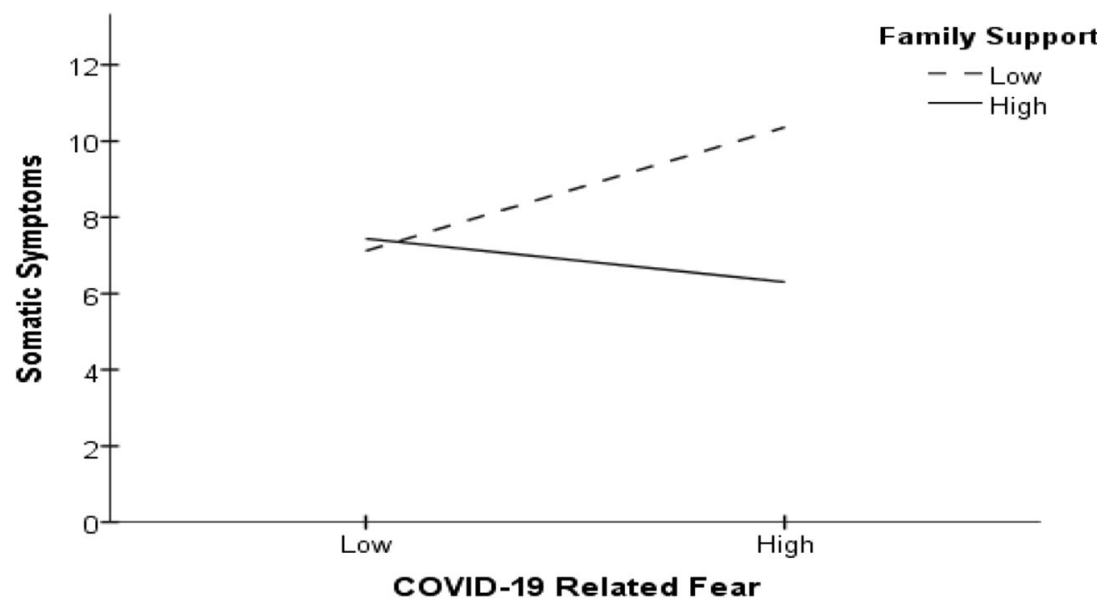


Table 4 Hierarchical regression results for anxiety (GAD). $(N=$ 163)

\begin{tabular}{|c|c|c|c|c|c|c|c|c|}
\hline \multirow[t]{2}{*}{ Variable } & \multirow[t]{2}{*}{$B$} & \multicolumn{2}{|c|}{$95 \%$ CI for $B$} & \multirow[t]{2}{*}{$S E B$} & \multirow[t]{2}{*}{$\beta$} & \multirow[t]{2}{*}{$s r^{2}$} & \multirow[t]{2}{*}{$R^{2}$} & \multirow[t]{2}{*}{$\Delta R^{2}$} \\
\hline & & Lower & Upper & & & & & \\
\hline Step 1 & & & & & & & .11 & $.11 * * *$ \\
\hline Gender & -1.28 & -2.97 & .41 & .86 & -.12 & .01 & & \\
\hline Marital Status ${ }^{\mathrm{a}}$ & $2.22 *$ & .29 & 4.15 & .98 & .19 & .03 & & \\
\hline Marital Status ${ }^{\mathrm{c}}$ & $6.07 * * *$ & 2.81 & 9.33 & 1.65 & .31 & .08 & & \\
\hline Step 2 & & & & & & & .20 & $.09 * * *$ \\
\hline Gender & -.76 & -2.39 & .87 & .82 & -.07 & .00 & & \\
\hline Marital Status ${ }^{\mathrm{a}}$ & $2.27 *$ & .44 & 4.11 & .93 & .20 & .03 & & \\
\hline Marital Status ${ }^{\mathrm{c}}$ & $5.89 * * *$ & 2.79 & 8.99 & 1.57 & .30 & .07 & & \\
\hline FCV-19S & $.31 * * *$ & .16 & .45 & .07 & .31 & .09 & & \\
\hline Step 3 & & & & & & & .30 & $.10 * * *$ \\
\hline Gender & -.42 & -2.02 & 1.18 & .81 & -.04 & .00 & & \\
\hline Marital Status ${ }^{\mathrm{a}}$ & 1.32 & -.56 & 3.19 & .95 & .11 & .01 & & \\
\hline Marital Status ${ }^{\mathrm{c}}$ & $5.61 * * *$ & 2.64 & 8.58 & 1.50 & .28 & .06 & & \\
\hline FCV-19S & $.29 * * *$ & .16 & .43 & .07 & .29 & .08 & & \\
\hline $\mathrm{FS}^{1}$ & $-.29 * * *$ & -.44 & -.14 & .08 & -.29 & .06 & & \\
\hline $\mathrm{FS}^{2}$ & -.06 & -.24 & .12 & .09 & -.06 & .00 & & \\
\hline SOS & .01 & -.16 & .17 & .08 & .01 & .00 & & \\
\hline Step 4 & & & & & & & .33 & .03 \\
\hline Gender & -.58 & -2.17 & 1.01 & .80 & -.05 & .00 & & \\
\hline Marital Status ${ }^{\mathrm{a}}$ & 1.17 & -.71 & 3.04 & .95 & .10 & .01 & & \\
\hline Marital Status ${ }^{\mathrm{c}}$ & $5.68 * * *$ & 2.74 & 8.63 & 1.49 & .29 & .06 & & \\
\hline FCV-19S & $.25 * * *$ & .12 & .39 & .07 & .26 & .06 & & \\
\hline $\mathrm{FS}^{1}$ & $-.29 * * *$ & -.44 & -.14 & .08 & -.29 & .06 & & \\
\hline $\mathrm{FS}^{2}$ & -.06 & -.24 & .12 & .09 & -.05 & .00 & & \\
\hline SOS & -.02 & -.19 & .14 & .08 & -.03 & .00 & & \\
\hline $\mathrm{FCV}-19 \mathrm{~S} \times \mathrm{FS}^{1}$ & -.51 & -1.44 & .43 & .47 & -.09 & .01 & & \\
\hline $\mathrm{FCV}-19 \mathrm{~S} \times \mathrm{FS}^{2}$ & .70 & -.26 & 1.66 & .49 & .13 & .01 & & \\
\hline FCV $-19 \mathrm{~S} \times \mathrm{SOS}$ & $-1.01 *$ & -1.94 & -.07 & .47 & -.18 & .02 & & \\
\hline
\end{tabular}

\section{Discussion}

The primary goal of this study was to examine the main and moderating effects of COVID-19 related fear and support system with Indian populations' mental health outcomes during
COVID-19 outbreak. Results were largely consistent with the stated hypotheses. For instance, a significant positive association was observed between COVID-19 related fear and mental health outcomes. This is consistent with previous findings among the general public (Wang et al., 2020) and individual
Fig. 2 Relationship between COVID-19 related fear and anxiety (GAD) at low and high levels of significant other support

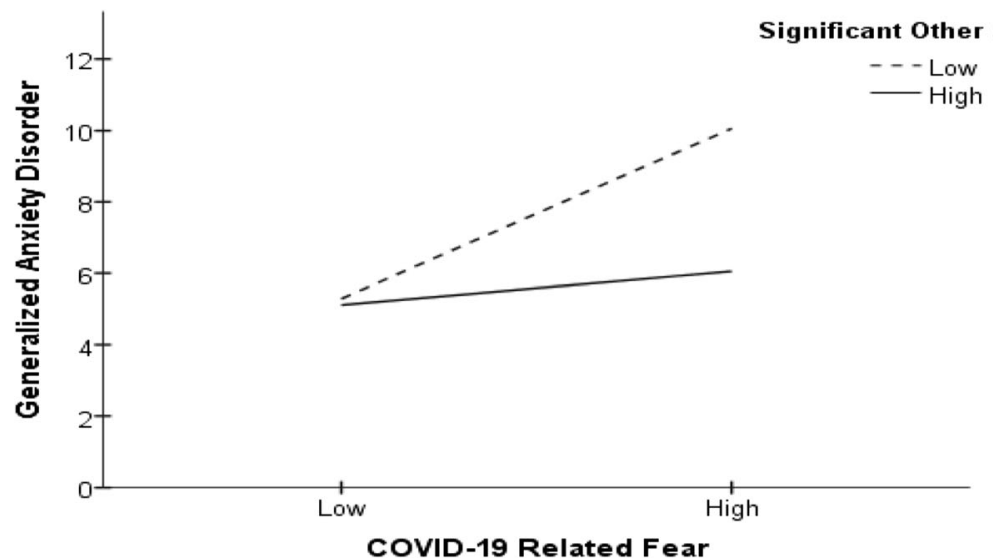


Table 5 Hierarchical regression results for depression. $(N=163)$

\begin{tabular}{|c|c|c|c|c|c|c|c|c|}
\hline \multirow[t]{2}{*}{ Variable } & \multirow[t]{2}{*}{$B$} & \multicolumn{2}{|c|}{$95 \%$ CI for $B$} & \multirow[t]{2}{*}{$S E B$} & \multirow[t]{2}{*}{$\beta$} & \multirow[t]{2}{*}{$s r^{2}$} & \multirow[t]{2}{*}{$R^{2}$} & \multirow[t]{2}{*}{$\Delta R^{2}$} \\
\hline & & Lower & Upper & & & & & \\
\hline Step 1 & & & & & & & .14 & $.14 * * *$ \\
\hline Gender & -.30 & -3.33 & 2.72 & 1.53 & -.02 & .00 & & \\
\hline Marital Status ${ }^{\mathrm{a}}$ & $6.81 * * *$ & 3.36 & 10.26 & 1.75 & .32 & .08 & & \\
\hline Marital Status ${ }^{\mathrm{c}}$ & $12.91 * * *$ & 7.09 & 18.73 & 2.95 & .36 & .10 & & \\
\hline Step 2 & & & & & & & .17 & $.03 *$ \\
\hline Gender & .21 & -2.81 & 3.22 & 1.53 & .01 & .00 & & \\
\hline Marital Status ${ }^{\mathrm{a}}$ & $6.86^{* * *}$ & 3.46 & 10.27 & 1.72 & .33 & .08 & & \\
\hline Marital Status ${ }^{\mathrm{c}}$ & $12.73 * * *$ & 6.98 & 18.49 & 2.91 & .35 & .10 & & \\
\hline FCV-19S & $.30 *$ & .04 & .56 & .13 & .17 & .03 & & \\
\hline Step 3 & & & & & & & .23 & $.06^{*}$ \\
\hline Gender & .46 & -2.59 & 3.51 & 1.54 & .02 & .00 & & \\
\hline Marital Status ${ }^{\mathrm{a}}$ & $5.22 * *$ & 1.64 & 8.81 & 1.81 & .25 & .04 & & \\
\hline Marital Status ${ }^{\mathrm{c}}$ & $12.19 * * *$ & 6.52 & 17.87 & 2.87 & .34 & .09 & & \\
\hline FCV-19S & $.27 *$ & .02 & .53 & .13 & .15 & .02 & & \\
\hline $\mathrm{FS}^{1}$ & $-.40^{* *}$ & -.69 & -.11 & .15 & -.22 & .04 & & \\
\hline $\mathrm{FS}^{2}$ & .01 & -.34 & .35 & .17 & .01 & .00 & & \\
\hline SOS & -.09 & -.40 & .22 & .16 & -.05 & .00 & & \\
\hline Step 4 & & & & & & & .28 & $.05^{*}$ \\
\hline Gender & .24 & -2.76 & 3.23 & 1.52 & .01 & .00 & & \\
\hline Marital Status ${ }^{\mathrm{a}}$ & $5.59^{* *}$ & 2.06 & 9.11 & 1.78 & .26 & .05 & & \\
\hline Marital Status ${ }^{\mathrm{c}}$ & $12.95 * * *$ & 7.40 & 18.50 & 2.81 & .36 & .10 & & \\
\hline FCV-19S & $.26^{*}$ & .01 & .53 & .13 & .15 & .02 & & \\
\hline $\mathrm{FS}^{1}$ & $-.35 *$ & -.64 & -.06 & .15 & -.20 & .03 & & \\
\hline $\mathrm{FS}^{2}$ & .01 & -.33 & .34 & .17 & .01 & .00 & & \\
\hline SOS & -.14 & -.45 & .17 & .16 & -.08 & .00 & & \\
\hline $\mathrm{FCV}-19 \mathrm{~S} \times \mathrm{FS}^{1}$ & -.60 & -2.36 & 1.16 & .89 & -.06 & .00 & & \\
\hline FCV-19S $\times \mathrm{FS}^{2}$ & $-2.06^{*}$ & -3.87 & -.24 & .92 & -.20 & .02 & & \\
\hline $\mathrm{FCV}-19 \mathrm{~S} \times \mathrm{SOS}$ & .03 & -1.74 & 1.79 & .89 & .01 & .00 & & \\
\hline
\end{tabular}

adjustment during the SARS epidemic in general public samples (Cheng \& Tang, 2004; Leppin \& Aro, 2009; Mihashi et al., 2009), reflecting the widespread effects of uncertainty and health-related fears. This is also in line with Khan et al.
(2020), suggesting that fear of a novel infection could be a strong determinant of pervasive anxiety. A recent study by Serafini et al. (2020) also indicated that generalized fear of COVID-19 was a prominent psychological response, which
Fig. 3 Relationship between COVID-19 related fear and depression at low and high levels of friends' support

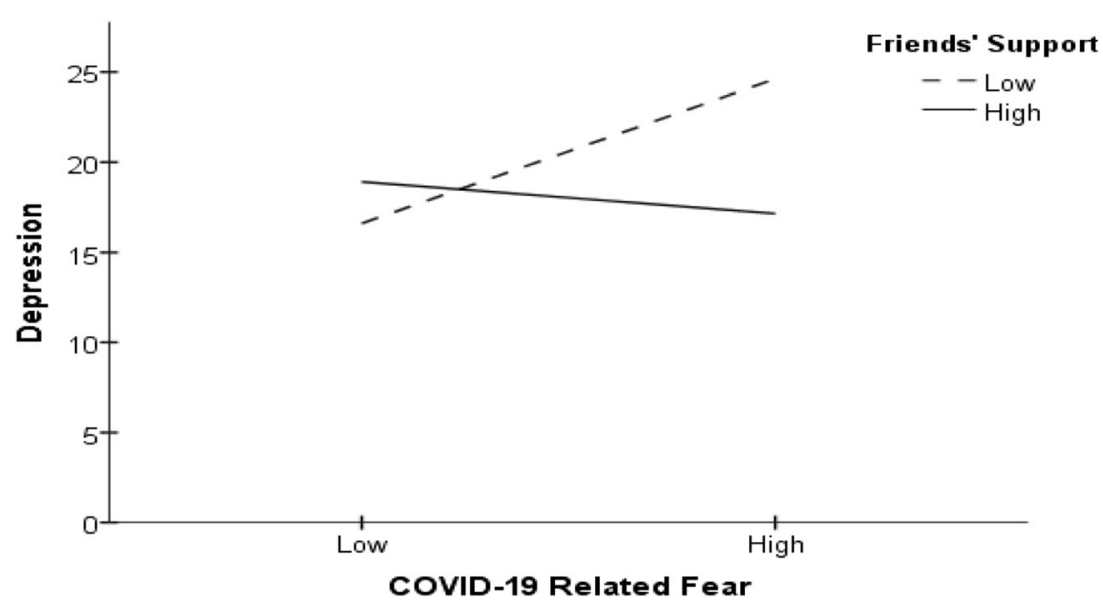


further led to community anxiety. Asmundson and Taylor (2020) coined the term 'coronaphobia', which they defined as the fear of the novel coronavirus. The researchers assert that this mass fear is accompanied by ambiguity, uncertainty aversion, perceived infection risk, maladaptive behavior, psychological distress, and avoidance reaction. Moreover, older studies have also established a clear role of pervasive fear elicited by an outbreak in the development of mental health problems (Jeong et al., 2016; Desclaux et al., 2017). It is, therefore, reasonable to posit that the fear of COVID-19 cannot be separated from its mental health ramifications. Thus, the mental health impact of the outbreak on the general population was significant, and thus, large-scale public health emergencies, such as COVID-19 pandemic can affect all shades of people irrespective of their underlying health conditions and other vulnerabilities.

However, there was a lack of anticipated relationship between COVID-19 related fear and support system. The direction of this relationship was negative but non-significant. This was somewhat similar to other studies of post-disaster recovery in youth and adult population (Dar et al., 2018; La Greca et al., 2010; Vernberg et al., 1996). In addition, this makes a theoretical sense because disasters may disrupt perceived social support networks through mechanisms such as family separation and difficulty maintaining peer connections, which may serve to confer risk by altering an individual's source of perceived social support that satisfy the need of social relatedness (Weems \& Overstreet, 2008).

Next, consistent with our hypothesis, support system was negatively associated with mental health outcomes. However, there was lack of statistical association between $\mathrm{FS}^{2}$ and depression as well as SOS and somatic symptoms. This is consistent with the psychological impact of the COVID-19 epidemic on college students in China (Cao et al., 2020) and postflood recovery in adult population in Kashmir, India (Dar et al., 2018). This makes sense, because weak support system may aggravate and strong support system may alleviate the negative mental health outcomes during or following public health emergencies, such as COVID-19 pandemic.

Prior researches that investigated the role of perceived social support in determining mental health of individuals amid COVID-19 yielded similar findings (Cao et al., 2020; Du et al., 2020). For instance, Serafini et al. (2020), a greater perception of social support is associated with a reduced likelihood of developing psychiatric condition and psychological disorders amid the ongoing pandemic. A support system is, indeed, crucial in times of global health crisis such as the ongoing COVID-19 crisis, in order to combat the difficulties posed by social isolation, boredom, and loneliness, that are often disabling enough to cause pervasive anxiety, suicidal behaviors, increased depression and panic (Khan et al., 2020; Lee $\&$ You, 2020; Orsolini et al., 2020).
The results of the present study also inform us about the nature of the relationship between COVID-19 related fear and mental health outcomes. As predicted, the results confirmed our hypothesis of support system as a moderator in the association between COVID-19 related fear and mental health outcomes. More specifically, low levels of perceived family support enhanced the association between COVID-19 related fear and somatic symptom whereas low level of significant others' support enhanced the relationship between COVID19 related fear and GAD. In addition, when the friends' support was low, the relationship between COVID-19 related fear and depression was robust. However, the association between COVID-19 related fear and mental health outcomes continued to remain non-significant in case the more support was available from any variant of support system. This is consistent with findings from previous studies (Dar et al., 2018; Marmot \& Wilkinson, 2005; Brummett et al., 2005) but increments the extant literature while demonstrating the buffering nature of support system during/following pandemics across multiple indices of psychological distress. Following a disaster, perceived support from others may alleviate physical and psychological distress, as this support demonstrates others' awareness of the situation and empathy (Mohay \& Forbes, 2009). Moreover, Brummett et al. (2005) assert that one of the key features of a support system is that it reassures the individual of the availability of physical and psychological buffer. The authors further posit that since support system provides a sense of security to the individuals experiencing psychosocial and physical distress, it directly improves the individual's mental well-being. Individuals who have stronger source of perceived social support tend to cope better with life stresses than do individuals who do not have such means of support (Cohen \& Wills, 1985). The perceived availability of perceived social support during stressful situations, such as following a natural disaster, is thought to aid an individual in the provision of psychological resources needed to cope with the situation, and therefore serve to buffer the effects of stress (Cohen, 2004).

The perception of available perceived social support may also result in the reduction or elimination of affective and physiological responses to the stressful event which, in turn, may alter potentially maladaptive behavioural responses (Cohen et al., 2000). In addition, perceived social support provides an outlet for individuals to voice their problems and concerns, which has been associated with a reduction in intrusive thoughts that can serve to maintain maladaptive responses to a stressful event (Cohen et al., 2000).

The present study observed support system exercising significant moderating effects between COVID-19 related fear and mental health outcomes. Among other potentially negative consequences, COVID-19 related fear may disorganize the support system, to the extent that people are likely to experience the feelings of separation, or isolation, and 
disconnectedness. Besides, these feelings may give rise to a vicious and repetitive cycle of thinking pattern in these individuals and, thereof, may substantially contribute in the emergence of mental health issues.

In addition, the study results also revealed a significant association between gender and mental health outcomes. As compared to male participants, females showed stronger association with somatic symptoms and GAD. This is in line with previous investigations (Mazza et al., 2020; Özdin \& Bayrak Özdin, 2020; Zhang et al., 2020) demonstrating that relative to men, women mental health was more severely affected during the ongoing COVID-19 pandemic. Moreover, Marital Status ${ }^{\mathrm{a}}$ showed positive association with depression and negative with $\mathrm{FS}^{1}$, and SOS, such that singles were more depressed, may be due to weak $\mathrm{FS}^{1}$ and SOS compared to their married counterparts. In contrast, Marital Status ${ }^{\mathrm{c}}$ was positively associated with mental health outcomes and SOS, suggesting that dating/engaged reported more somatic symptoms, GAD, and depression despite strong SOS against the married participants.

\section{Implications}

Based on the study findings, the robust and consistent support system might lessen the psychological sequelae amid COVID-19 pandemic. Thus, we believe that these results encourage professionals to explore with their clients the availability and robustness of support system in times of crises, such as COVID-19 pandemic. The professionals should also explore the ways with their clients how best the different variants of support system could be incremented to lessen the mental health issues amid or following COVID-19 pandemic.

\section{Limitations}

The present study has certain limitations. First, this study is cross-sectional in nature making it impossible to draw conclusions on cause-effect relations. Therefore, longitudinal studies that may reveal causal effects, are warranted. Second, all the constructs were assessed by self-report measures, the estimated relations among study's variables might be biased by reporter effect. Future research should use a multi-informant and multimethod approach to assessment. Third, not all the measures used in the current study are validated on Indian population, and thus, prospective researchers should validate them before use. Last, the data for the present study were collected through the online platform using Google Form. There is a possibility of irrational and misleading feedbacks. Thus, future researchers should explore a mechanism that enables them to monitor the data collection process.

\section{Conclusions}

In summary, the results demonstrate that robust support system may be a protective factor against experienced somatic symptoms, GAD, and depression during the COVID-19 outbreak. The mental health of general masses is significantly affected when faced with public health emergencies, and they require support of the family, friends, and significant others. Thus, it is suggested that all stakeholders, including professionals, government, and semi or non-government organizations should collaborate and provide all possible support and services to people during the emergencies. In addition, professionals should explore with their clients the support system and design strategies toward improving the mental health of their clients.

Acknowledgements We wish to thank those who kindly volunteered to participate in the present study amid ongoing COVID-19 pandemic. The authors also wish to thank the corresponding author's son, Muhammad Affan, for being supportive with this work.

Code Availability Not applicable.

Authors' Contributions Kaiser Ahmad Dar and Naved Iqbal developed the study concept and contributed to the study design. Alina Suhail managed the literature searches and data collection. Kaiser Ahmad Dar performed the data analysis and interpretation. Both Kaiser Ahmad Dar and Alina Suhail drafted the manuscript, and Naved Iqbal provided critical revisions. All authors contributed to and approved the final version of the manuscript for submission.

Data Availability The data that support the findings of this study are available from the corresponding author upon reasonable request.

\section{Declarations}

Conflict of Interest The authors declare that there are no potential conflicts of interest with respect to the research, authorship, and/or publication of this article.

\section{References}

Ahorsu, D. K., Lin, C. Y., Imani, V., Saffari, M., Griffiths, M. D., \& Pakpour, A. H. (2020). The fear of COVID-19 scale: Development and initial validation. International Journal of Mental Health and Addiction, 1-9. Advance online publication. https://doi.org/10.1007/s11469-020-00270-8.

Aiken, L. S., West, S. G., \& Reno, R. R. (1991). Multiple regression: Testing and interpreting interactions. Sage.

Arslan, G., Yıldırım, M., Tanhan, A., Buluş, M., \& Allen, K. A. (2020). Coronavirus stress, optimism-pessimism, psychological inflexibility, and psychological health: Psychometric properties of the coronavirus stress measure. International Journal of Mental Health and Addiction, 1-17. https://doi.org/10.31234/osf.io/n6dcj.

Ashour, H. M., Elkhatib, W. F., Rahman, M., \& Elshabrawy, H. A. (2020). Insights into the recent 2019 novel coronavirus (SARS- 
CoV-2) in light of past human coronavirus outbreaks. Pathogens, 9, 186. https://doi.org/10.3390/pathogens9030186.

Asmundson, G. J., \& Taylor, S. (2020). Coronaphobia: Fear and the 2019-nCoV outbreak. Journal of Anxiety Disorders, 70, 102196. https://doi.org/10.1016/j.janxdis.2020.102196.

Balkhair, A. A. (2020). COVID-19 pandemic: A new chapter in the history of infectious diseases. Oman Medical Journal, 35, e123. https://doi.org/10.5001/omj.2020.41.

Banerjee, D. (2020). The COVID-19 outbreak: Crucial role the psychiatrists can play. Asian Journal of Psychiatry, 50, 102014. https://doi. org/10.1016/j.ajp.2020.102014.

Bao, Y., Sun, Y., Meng, S., Shi, J., \& Lu, L. (2020). 2019-nCoV epidemic: Address mental health care to empower society. The Lancet, 395, e37-e38. https://doi.org/10.1016/S0140-6736.

Baron, R. M., \& Kenny, D. A. (1986). The moderator-mediator variable distinction in social psychological research: Conceptual, strategic, and statistical considerations. Journal of Personality and Social Psychology, 51, 1173-1182. https://doi.org/10.1037/0022-3514. 51.6.1173.

Brooks, S. K., Webster, R. K., Smith, L. E., Woodland, L., Wessely, S., Greenberg, N., \& Rubin, G. J. (2020). The psychological impact of quarantine and how to reduce it: Rapid review of the evidence. The Lancet, 395, 912-920. https://doi.org/10.1016/S0140-6736(20) 30460-8.

Brummett, B. H., Mark, D. B., Siegler, I. C., Williams, R. B., Babyak, M. A., Clapp-Channing, N. E., \& Barefoot, J. C. (2005). Perceived social support as a predictor of mortality in coronary patients: Effects of smoking, sedentary behavior, and depressive symptoms. Psychosomatic Medicine, 67, 40-45. https://doi.org/10.1097/01. psy.0000149257.74854.b7.

Cao, W., Fang, Z., Hou, G., Han, M., Xu, X., Dong, J., \& Zheng, J. (2020). The psychological impact of the COVID-19 epidemic on college students in China. Psychiatry Research, 287, 112934. https://doi.org/10.1016/j.psychres.2020.112934.

Chatterjee, P., Nagi, N., Agarwal, A., Das, B., Banerjee, S., Sarkar, S., Gupta, N., \& Gangakhedkar, R. R. (2020). The 2019 novel coronavirus disease (COVID-19) pandemic: A review of the current evidence. Indian Journal of Medical Research., 151, 147-159. https:// doi.org/10.4103/ijmr.IJMR 519 20.

Cheng, C., \& Tang, C. S. (2004). The psychology behind the masks: Psychological responses to the severe acute respiratory syndrome outbreak in different regions. Asian Journal of Social Psychology, 7, 3-7. https://doi.org/10.1111/j.1467-839X.2004.00130.x.

Cohen, J., Cohen, P., West, S. G., \& Aiken, L. S. (2013). Applied multiple regression/correlation analysis for the behavioral sciences. Routledge. https://doi.org/10.4324/9780203774441.

Cohen, S. (2004). Social relationships and health. American Psychologist, 59, 676-684. https://doi.org/10.1037/0003-066X.59.8.676.

Cohen, S., Underwood, L. G., \& Gottlieb, B. H. (Eds.). (2000). Social support measurement and intervention: A guide for health and social scientists. New York: Oxford University Press.

Cohen, S., \& Wills, T. A. (1985). Stress, social support, and the buffering hypothesis. Psychological Bulletin, 98, 310-357. https://doi.org/10. 1037/0033-2909.98.2.310

Dar, K. A., Iqbal, N., Prakash, A., \& Paul, M. A. (2018). PTSD and depression in adult survivors of flood fury in Kashmir: The payoffs of social support. Psychiatry Research, 261, 449-455. https://doi. org/10.1016/j.psychres.2018.01.023.

Desclaux, A., Badji, D., Ndione, A. G., \& Sow, K. (2017). Accepted monitoring or endured quarantine? Ebola contacts' perceptions in Senegal. Social Science \& Medicine, 178, 38-45. https://doi.org/ 10.1016/j.socscimed.2017.02.009.

Du, J., Dong, L., Wang, T., Yuan, C., Fu, R., Zhang, L., et al. (2020). Psychological symptoms among frontline healthcare workers during COVID-19 outbreak in Wuhan. General Hospital Psychiatry., 67, 144-145. https://doi.org/10.1016/j.genhosppsych.2020.03.011.
El-Zoghby, S. M., Soltan, E. M., \& Salama, H. M. (2020). Impact of the COVID-19 pandemic on mental health and social support among adult Egyptians. Journal of Community Health, 45, 689-695. https://doi.org/10.1007/s10900-020-00853-5.

Faul, F., Erdfelder, E., Lang, A. G., \& Buchner, A. (2007). G* power 3: A flexible statistical power analysis program for the social, behavioral, and biomedical sciences. Behavior Research Methods, 39, 175-191. https://doi.org/10.3758/BF03193146.

Frazier, P. A., Tix, A. P., \& Barron, K. E. (2004). Testing moderator and mediator effects in counseling psychology research. Journal of Counseling Psychology, 51, 115-134. https://doi.org/10.1037/ 0022-0167.51.1.115.

Gierk, B., Kohlmann, S., Kroenke, K., Spangenberg, L., Zenger, M., Brähler, E., \& Löwe, B. (2014). The somatic symptom scale-8 (SSS-8): A brief measure of somatic symptom burden. JAMA Internal Medicine, 174, 399-407. https://doi.org/10.1001/ jamainternmed.2013.12179.

Harandi, T. F., Taghinasab, M. M., \& Nayeri, T. D. (2017). The correlation of social support with mental health: A meta-analysis. Electronic Physician, 9, 5212-5222. https://doi.org/10.19082/5212.

Hayes, A. F. (2018). Introduction to mediation, moderation, and conditional process analysis: A regression-based approach. The Guilford Press.

Huang, Y., \& Zhao, N. (2020). Generalized anxiety disorder, depressive symptoms and sleep quality during COVID-19 outbreak in China: A web-based cross-sectional survey. Psychiatry Research, 288, 112954. https://doi.org/10.1016/j.psychres.2020.112954.

Jeong, H., Yim, H. W., Song, Y. J., Ki, M., Min, J. A., Cho, J., Chae J.H. (2016). Mental health status of people isolated due to Middle East Respiratory Syndrome. Epidemiology and Health, 38. https://doi. org/10.4178/epih.e2016048

Khan, S., Siddique, R., Li, H., Ali, A., Shereen, M. A., Bashir, N., \& Xue, M. (2020). Impact of coronavirus outbreak on psychological health. Journal of Global Health, 10. https://doi.org/10.7189/jogh.10. 010331.

Kroenke, K., Spitzer, R. L., Williams, J. B., \& Löwe, B. (2010). The patient health questionnaire somatic, anxiety, and depressive symptom scales: A systematic review. General Hospital Psychiatry, 32, 345-359. https://doi.org/10.1016/j.genhosppsych.2010.03.006.

Kumar, A., \& Nayar, K. R. (2020). COVID 19 and its mental health consequences. Journal of Mental Health, 30, 1-2. https://doi.org/ 10.1080/09638237.2020.1757052.

La Greca, A. M., Silverman, W. K., Lai, B., \& Jaccard, J. (2010). Hurricane-related exposure experiences and stressors, other life events, and social support: Concurrent and prospective impact on children's persistent posttraumatic stress symptoms. Journal of Consulting and Clinical Psychology, 78, 794-805. https://doi.org/ 10.1037/a0020775.

Lee, M., \& You, M. (2020). Psychological and behavioral responses in South Korea during the early stages of coronavirus disease 2019 (COVID-19). International Journal of Environmental Research and Public Health, 17, 2977. https://doi.org/10.3390/ ijerph17092977.

Leppin, A., \& Aro, A. R. (2009). Risk perceptions related to SARS and avian influenza: Theoretical foundations of current empirical research. International Journal of Behavioral Medicine, 16, 7-29. https://doi.org/10.1007/s12529-008-9002-8.

Lima, C. K. T., de Medeiros Carvalho, P. M., Lima, I. D. A. S., de Oliveira Nunes, J. V. A., Saraiva, J. S., de Souza, R. I., et al. (2020). The emotional impact of coronavirus 2019-nCoV (new coronavirus disease). Psychiatry Research, 112915, 112915. https:// doi.org/10.1016/j.psychres.2020.112915.

Lin, C. Y. (2020). Social reaction toward the 2019 novel coronavirus (COVID-19). Social Health and Behavior, 3, 1. https://doi.org/10. 4103/SHB.SHB_11_20. 
Marmot, M., \& Wilkinson, R. (Eds.). (2005). Social determinants of health. OUP, Oxford. https://doi.org/10.1093/acprof:oso/ 9780198565895.001.0001.

Mazza, C., Ricci, E., Biondi, S., Colasanti, M., Ferracuti, S., Napoli, C., \& Roma, P. (2020). A nationwide survey of psychological distress among italian people during the COVID-19 pandemic: Immediate psychological responses and associated factors. International Journal of Environmental Research and Public Health, 17, 3165. https://doi.org/10.3390/ijerph17093165.

Mihashi, M., Otsubo, Y., Yinjuan, X., Nagatomi, K., Hoshiko, M., \& Ishitake, T. (2009). Predictive factors of psychological disorder development during recovery following SARS outbreak. Health Psychology, 28, 91-100. https://doi.org/10.1037/a0013674.

Mohay, H., \& Forbes, N. (2009). Reducing the risk of posttraumatic stress disorder in children following natural disasters. Journal of Psychologists and Counsellors in Schools, 19, 179-195. https:// doi.org/10.1375/ajgc.19.2.179.

Nunnaly, J. C. (1994). Psychometric theory. McGraw-Hill.

Orsolini, L., Latini, R., Pompili, M., Serafini, G., Volpe, U., Vellante, F., et al. (2020). Understanding the complex of suicide in depression: From research to clinics. Psychiatry Investigation, 17, 207-221. https://doi.org/10.30773/pi.2019.0171.

Özdin, S., \& Bayrak Özdin, S.. (2020). Levels and predictors of anxiety, depression and health anxiety during COVID-19 pandemic in Turkish society: The importance of gender. International Journal of Social Psychiatry, 0020764020927051. https://doi.org/10.1177/ 0020764020927051.

Radloff, L. S. (1977). The CES-D scale: A self-report depression scale for research in the general population. Applied Psychological Measurement, 1, 385-401. https://doi.org/10.1177/ 014662167700100306.

Rajkumar, R. P. (2020). COVID-19 and mental health: A review of the existing literature. Asian Journal of Psychiatry, 102066, 102066. https://doi.org/10.1016/j.ajp.2020.102066.

Roy, D., Tripathy, S., Kar, S. K., Sharma, N., Verma, S. K., \& Kaushal, V. (2020). Study of knowledge, attitude, anxiety \& perceived mental healthcare need in Indian population during COVID-19 pandemic. Asian journal of psychiatry, 102083. https://doi.org/10.1016/j.ajp. 2020.102083

Rubin, G. J., \& Wessely, S. (2020). The psychological effects of quarantining a city. British Medical Journal, 368. https://doi.org/ 10.1136/bmj.m313.

Salari, N., Hosseinian-Far, A., Jalali, R., Vaisi-Raygani, A., Rasoulpoor, S., Mohammadi, M., Rasoulpoor, S., \& Khaledi-Paveh, B. (2020). Prevalence of stress, anxiety, depression among the general population during the COVID-19 pandemic: A systematic review and meta-analysis. Globalization and Health, 16, 1-11. https://doi.org/10. 1186/s12992-020-00589-w.

Sarangi, A. (2020). The emerging mental health impact of COVID-19 pandemic: Can India cope? In The citizen Retrieved from https:// www.thecitizen.in/index.php/en/NewsDetail/index/15/18569/.

Serafini, G., Parmigiani, B., Amerio, A., Aguglia, A., Sher, L., \& Amore, M. (2020). The psychological impact of COVID-19 on the mental health in the general population. QJM: An International Journal of Medicine, 113, 531-537. https://doi.org/10.1093/qjmed/hcaa201.

Spitzer, R. L., Kroenke, K., Williams, J. B., \& Löwe, B. (2006). A brief measure for assessing generalized anxiety disorder: The GAD 7. Archives of Internal Medicine, 166, 1092-1097. https://doi.org/10. 1001/archinte.166.10.1092.

Tanhan, A., Yavuz, K. F., Young, J. S., Nalbant, A., Arslan, G., Yıldırım, M., ... \& Çiçek, İ. (2020). A proposed framework based on literature review of online contextual mental health services to enhance wellbeing and address psychopathology during COVID-19. Electronic Journal of General Medicine, 17, em254. https://doi. org/10.29333/ejgm/8316

Vernberg, E. M., La Greca, A. M., Silverman, W. K., \& Prinstein, M. J. (1996). Prediction of posttraumatic stress symptoms in children after hurricane Andrew. Journal of Abnormal Psychology, 105, 237-248. https://doi.org/10.1037/0021-843X.105.2.237.

Wang, Y., Wan, Q., Huang, Z., Huang, L., \& Kong, F. (2017). Psychometric Properties of Multi-Dimensional Scale of Perceived Social Support in Chinese Parents of Children with Cerebral Palsy. Frontiers in Psychology, 8, 2020. https://doi.org/10.3389/fpsyg. 2017.02020

Wang, C., Pan, R., Wan, X., Tan, Y., Xu, L., Ho, C. S., \& Ho, R. C. (2020). Immediate psychological responses and associated factors during the initial stage of the 2019 coronavirus disease (COVID-19) epidemic among the general population in China. International Journal of Environmental Research and Public Health, 17, 1729. https://doi.org/10.3390/ijerph17051729.

Weems, C. F., \& Overstreet, S. (2008). Child and adolescent mental health research in the context of hurricane Katrina: An ecological needs-based perspective and introduction to the special section. Journal of Clinical Child \& Adolescent Psychology, 37, 487-494. https://doi.org/10.1080/15374410802148251.

Xiao, H., Zhang, Y., Kong, D., Li, S., \& Yang, N. (2020). The effects of social support on sleep quality of medical staff treating patients with coronavirus disease 2019 (COVID-19) in January and February 2020 in China. Medical Science Monitor: International Medical Journal of Experimental and Clinical Research, 26, e923549e923541. https://doi.org/10.12659/MSM.923549.

Zandifar, A., \& Badrfam, R. (2020). Iranian mental health during the COVID-19 epidemic. Asian Journal of Psychiatry, 51, 101990. https://doi.org/10.1016/j.ajp.2020.101990.

Zhang, J., Lu, H., Zeng, H., Zhang, S., Du, Q., Jiang, T., et al. (2020). The differential psychological distress of populations affected by the COVID-19 pandemic. Brain, Behavior, and Immunity, 87, 49-50. https://doi.org/10.1016/j.bbi.2020.04.031.

Zimet, G. D., Dahlem, N. W., Zimet, S. G., \& Farley, G. K. (1988). The multidimensional scale of perceived social support. Journal of Personality Assessment, 52, 30-41. https://doi.org/10.1207/ s15327752jpa5201_2.

Publisher's Note Springer Nature remains neutral with regard to jurisdictional claims in published maps and institutional affiliations. 